\title{
Hubungan Masa Kosong dengan Produktivitas pada Sapi Perah Friesian Holstein di Baturraden, Indonesia
}

The Impact of Days Open on Milk Performance of Friesian Holstein Cows in Baturraden, Indonesia

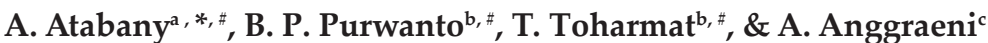 \\ a'Departemen Ilmu Produksi dan Teknologi Peternakan, Fakultas Peternakan, Institut Pertanian Bogor \\ bDepartemen Ilmu Nutrisi dan Teknologi Pakan, Fakultas Peternakan, Institut Pertanian Bogor \\ "Jln. Agatis Kampus IPB Darmaga, Bogor 16680 \\ 'Balai Penelitian Ternak \\ Jln. Veteran III, Desa Banjarwaru, Ciawi-Bogor 16002 \\ (Diterima 05-11-2009; disetujui 13-12-2010)
}

\begin{abstract}
ABSTRAK
Masa kosong (days open) merupakan salah satu faktor penentu produksi susu. Penelitian ini bertujuan untuk mengkaji pengaruh masa kosong terhadap produksi susu setara dewasa (SD) 305 hari. Materi penelitian berupa 150 catatan mingguan produksi susu dari 50 ekor sapi Friesian Holstein (FH) di Balai Besar Pembibitan Ternak Unggul (BBPTU) Sapi Perah Baturraden, Purwokerto, Jawa Tengah. Produksi susu dihitung dengan menggunakan time interval method (TIM) kemudian disetarakan dewasa 305 hari. Data dianalisis menggunakan model regresi polinomial. Pengaruh masa kosong terhadap produksi susu sangat nyata pada bentuk kuadratik dan kubik. Sapi memiliki masa kosong 138,77 hari. Berdasarkan persamaan model regresi kuadratik, peningkatan masa kosong akan menyebabkan penurunan produksi susu dan mencapai titik minimum pada masa kosong 169 hari.
\end{abstract}

Kata kunci: masa kosong, Friesian Holstein, produksi susu, Baturraden

\section{ABSTRACT}

Productivity of dairy cows not only expresed by milk yield, but also the reproductive performance. General speaking that the milk yield depends on reproductive performance and vice versa. The present study was conducted to observe the milk yield and reproductive performance of Friesian Holstein (FH) dairy cows. This study was conducted using 150 sets of weekly recording of milk yield from $50 \mathrm{FH}$ cows. Milk yield was calculated by using time interval method (TIM) which was equivalent to ME 305 days. The data were analysed using polynomial regression model. Results of the study indicated that the effect of days open on milk yield had significant effect on quadratic and qubic regression model. The average days open was 138.77 days. According to the quadratic regression model, increasing days open decreased milk yield and the minimum milk yield was observed at 169 days open.

Key words: days open, Friesian Holstein, milk yield, Baturraden

\section{PENDAHULUAN}

Bangsa sapi Friesian Holstein (FH) memiliki produksi susu tertinggi dibandingkan bangsa-bangsa sapi perah lainnya. Sapi $\mathrm{FH}$ mengalami peningkatan produksi susu sebanyak $23 \%$ selama periode 25 tahun

\footnotetext{
* Korespondensi:

Departemen Ilmu Produksi dan Teknologi Peternakan, Fakultas Peternakan, Institut Pertanian Bogor

Jln. Agatis Kampus IPB Darmaga, Bogor 16680

e-mail: bpp030560@yahoo.com
}

(Webster, 1993). Menurut Dematewewa et al. (2007), sapi FH mempunyai masa laktasi panjang dan produksi susu yang tinggi dengan puncak produksi susu dan persistensi produksi susu yang baik. Sapi dengan persistensi laktasi yang tinggi akan lebih panjang masa produksinya (Cole \& Null, 2003). Namun demikian produksi susu per ekor per hari pada sapi perah FH di Indonesia relatif rendah jika dibandingkan dengan produksi susu di negara asalnya.

Peningkatan produksi susu pada dasarnya dapat dilakukan melalui perbaikan mutu genetik dan manipulasi lingkungan, serta perbaikan manajemen 
pemeliharaan. Salah satu perbaikan manajemen yang dapat dilakukan, yaitu perbaikan masa kosong. Masa kosong atau days open adalah jarak waktu beranak sampai terjadi kebuntingan atau hari-hari dari setelah beranak sampai bunting. Periode masa kosong adalah 85-115 hari setelah beranak (Izquierdo et al., 2008). Ali et al. (2000) menambahkan bahwa tidak ada masa kosong yang kurang dari 30 hari. Masa kosong pada sapi perah FH di Rawa Seneng, Temanggung, Jawa Tengah berkisar 120-196 hari (Toharmat et al., 2007). Menurut Pszczola et al. (2009), sapi FH di Amerika Serikat mempunyai masa kosong terpanjang pada musim semi dan terpendek pada musim gugur. Variasi suhu yang tinggi dengan kombinasi kelembaban mempengaruhi masa kosong dan kesuburan karena menimbulkan kelainan fisiologis, sistem pencernaan, dan hormon di dalam darah. Lee et al. (1997) menyatakan bahwa sapi-sapi FH yang mempunyai produksi susu lebih tinggi pada awal laktasi memiliki masa kosong yang lebih panjang.

Setelah beranak sapi perah induk memerlukan waktu untuk mempersiapkan kebuntingan berikutnya. Masa kosong merupakan salah satu pengukuran indikator kesuburan pada ternak perah dan dipengaruhi banyak faktor, diantaranya musim beranak dan umur sapi (Oseni et al., 2003), panjang masa laktasi (Grossman \& Koops, 2003), periode laktasi (Mitchell et al., 2005), jenis kelamin anak yang dilahirkan (Izquierdo et al., 2008), dan tingkat produksi susu (Brotherstone et al., 2003). Sehingga masa kosong akan berpengaruh terhadap produksi susu pada laktasi berikutnya.

Salah satu masalah utama yang dialami oleh sebagian besar peternak sapi perah di Indonesia adalah masa kosong, jarak waktu antar melahirkan dan masa laktasi yang semakin lama melewati batas ideal. Oleh karena itu perlu diteliti pengaruh masa kosong terhadap produksi susu laktasi berikutnya untuk menerapkan manajemen pemeliharaan yang tepat.

\section{MATERI DAN METODE}

\section{Lokasi}

Penelitian dilaksanakan di Balai Besar Pembibitan Ternak Unggul (BBPTU) Sapi Perah Baturraden, Purwokerto, Jawa Tengah. Lokasi penelitian ini mempunyai suhu udara minimum $18{ }^{\circ} \mathrm{C}$ dan suhu maksimum $28^{\circ} \mathrm{C}$, dengan kelembaban udara $70 \%-80 \%$ serta curah hujan per tahun 6000-9000 mm.

\section{Materi}

Materi penelitian berupa data sekunder yang diperoleh dari catatan produksi dan reproduksi sapi laktasi di BBPTU Sapi Perah Baturraden, Purwokerto, Jawa Tengah. Data sekunder yang dikumpulkan meliputi produksi susu mingguan (dua kali pemerahan pada pukul 02.00 dan 14.00 setiap hari), tanggal lahir, tanggal beranak, tanggal inseminasi yang menghasilkan kebuntingan, dan tanggal kering kandang dari setiap ekor induk sapi. Data sekunder tersebut berasal dari induk sapi yang beranak pada tahun 1991 sampai dengan 2001. Data sapi perah yang digunakan berasal dari 50 ekor induk dan masing-masing data sampai laktasi ke-3 sehingga pencatatan berasal dari 150 laktasi.

Pemberian pakan dilakukan dua kali dalam sehari, yaitu pukul 06.00 dan pukul 14.00, dengan jumlah pemberian mengikuti standar pemeliharaan di BBPTU. Jumlah pemberian konsentrat dan hijauan dapat dilihat pada Tabel 1. Adapun komposisi bahan-bahan konsentrat dapat dilihat pada Tabel 2 dengan hasil analisis laboratorium terhadap bahan baku konsentrat dan hijauan dapat dilihat pada Tabel 3.

\section{Rancangan Percobaan dan Analisis Data}

Analisis data dilakukan dengan menggunakan analisis polinomial dengan model matematika mengacu pada Steel \& Torrie (1997) yang tertulis sebagai berikut:

$$
\begin{array}{ll}
\text { Linier } & : Y_{i}=b_{0}+b_{1} X+e_{i} \\
\text { Kuadratik } & : Y_{i}=b_{0}+b_{1} X+b_{2} X^{2}+e_{i} \\
\text { Kubik } & : Y_{i}=b_{0}+b_{1} X+b_{2} X^{2}+b_{3} X^{3}+e_{i} \\
Y_{i} & : \text { produksi susu dari catatan ke-i } \\
X & : \text { masa kosong }
\end{array}
$$

Tabel 1. Jumlah pemberian konsentrat dan hijauan pada sapi perah di Balai Besar Pembibitan Ternak Unggul (BBPTU) Baturraden

\begin{tabular}{lccc}
\hline Komposisi & $\begin{array}{c}\text { Umur } \\
(\text { bulan })\end{array}$ & $\begin{array}{c}\text { Konsentrat } \\
(\mathrm{kg})\end{array}$ & $\begin{array}{c}\text { Hijauan } \\
(\mathrm{kg})\end{array}$ \\
\hline Pedet & $0-2$ & 0,5 & 5 \\
& $2-4$ & 1,0 & 10 \\
& $4-6$ & 1,5 & 15 \\
Dara & $6-8$ & 2,0 & 20 \\
& $8-10$ & 2,5 & 25 \\
& $10-12$ & 3,0 & 25 \\
Dara besar & $12-14$ & 4,0 & 40 \\
& 15 & 4,5 & 45 \\
& 18 & 5,0 & 50 \\
Sapi dewasa & $>20$ & $5-6$ & 55 \\
\hline
\end{tabular}

Sumber: BBPTU sapi perah Baturraden (2002).

Tabel 2. Komposisi bahan baku konsentrat yang digunakan di Balai Besar Pembibitan Ternak Unggul (BBPTU) Baturraden (\%)

\begin{tabular}{lccc}
\hline Bahan baku & Dewasa & Dara & Pedet \\
\hline Bekatul & 23 & 30 & 23 \\
Tepung jagung & 10 & 5 & 25 \\
Bungkil kelapa & 15 & 20 & 5 \\
Pollard & 15 & 18 & 20 \\
Onggok & 15 & 25 & 5 \\
Ampas tahu & 20 & 0 & 20 \\
Mineral & 2 & 2 & 2 \\
\hline
\end{tabular}

Sumber: BBPTU sapi perah Baturraden (2002). 
Tabel 3. Hasil uji laboratorium komponen ransum pakan sapi perah di Balai Besar Pembibitan Ternak Unggul (BBPTU) Baturraden

\begin{tabular}{lccccrcc}
\hline Bahan & Air & Abu (\%BK) & PK (\%BK) & Lemak (\%BK) & SK (\%BK) & BETN (\%BK) & GE (kal/g) \\
\hline King grass & 85,47 & 11,94 & 12,57 & 2,48 & 30,69 & 42,32 & 1804,97 \\
Konsentrat karantina & 12,43 & 11,94 & 17,95 & 2,98 & 18,81 & 48,82 & 2519,66 \\
Konsentrat dewasa & 10,94 & 11,94 & 21,44 & 6,46 & 9,9 & 50,26 & 2578,83 \\
Konsentrat pedet & 12,43 & 10,94 & 13,13 & 3,48 & 7,92 & 64,53 & 2461,95 \\
\hline
\end{tabular}

Sumber: BBPTU sapi perah Baturraden (2002).

$$
\begin{array}{ll}
\mathrm{B}_{0} & : \text { intersep } \\
\mathrm{b}_{1}, \mathrm{~b}_{2}, \mathrm{~b}_{3} & : \text { koefisien regresi parsial } \\
\mathrm{e}_{\mathrm{i}} & : \text { galat }
\end{array}
$$

Model terbaik yang memiliki $\mathrm{R}^{2}$ paling tinggi dipilih dari ketiga model regresi tersebut. Apabila terdapat dua atau lebih model memiliki $\mathrm{R}^{2}$ sama maka dipilih model yang lebih sederhana.

Data produksi susu yang diperoleh diestimasi menggunakan Test Interval Method (TIM) menurut model estimasi yang digunakan pada penelitian Norman et al. (1999) yang tertulis sebagai berikut:

$$
\begin{aligned}
\text { Ye } & =\mathrm{d} / 2(\mathrm{y} 1+\mathrm{y} 2) \\
\mathrm{Ye} & =\text { produksi susu estimasi } \\
\mathrm{d} & =\text { selang hari pemerahan } \mathrm{y} 1 \text { dengan } \mathrm{y} 2 \\
\mathrm{yi} & =\text { produksi susu pemerahan pertama } \\
\mathrm{y} 2 & =\text { produksi susu pemerahan ke dua }
\end{aligned}
$$

\section{Peubah yang Digunakan}

Peubah yang diamati meliputi umur beranak, masa kosong, masa laktasi dan produksi susu, jarak waktu kawin pertama setelah beranak, service per conception (S/C), dan selang waktu beranak. Umur beranak merupakan umur induk sapi saat beranak yang diperoleh dari beranak pertama, kedua, ketiga, dan keempat. Umur beranak diperoleh dengan menghitung jumlah hari antara tanggal lahir induk sapi hingga tanggal beranak pertama, kedua, ketiga, dan keempat. Masa kosong adalah rentang waktu (dihitung dalam hari) dari induk sapi beranak sampai sapi tersebut dikawin kembali yang menghasilkan kebuntingan.

Masa laktasi adalah periode atau lamanya sapi diperah (dihitung dalam hari) untuk memproduksi susu yaitu dari awal sapi beranak hingga sapi dikeringkandangkan. Produksi susu diperoleh dari catatan mingguan yang telah diestimasi menggunakan Test Interval Method (TIM). Produksi susu kemudian disetarakan dewasa 305 hari untuk mengurangi keragaman produksi susu karena faktor umur dari masa laktasi (dalam kg).

Jarak waktu kawin pertama setelah beranak adalah jarak waktu (dihitung dalam hari) antara induk sapi beranak sampai induk sapi tersebut dikawinkan kembali. Service per conception adalah jumlah perkawinan atau inseminasi yang dibutuhkan oleh seekor sapi betina sampai menghasilkan kebuntingan. Selang beranak adalah jangka waktu (dihitung dalam hari) dari saat induk beranak hingga saat beranak berikutnya.
Faktor koreksi produksi susu setara dewasa (SD) 305 hari menurut Hardjosubroto (1994) adalah (1) menggunakan faktor koreksi 1,0 untuk panjang laktasi 305-308 hari; (2) menggunakan faktor koreksi di atas 1,0 apabila panjang laktasi kurang dari 305 hari; dan (3) menggunakan faktor koreksi di bawah 1,0 apabila panjang laktasi lebih dari 308 hari. Sebagai contoh adalah apabila panjang laktasi 270, 280, 290, dan 300 hari maka faktor koreksinya adalah 1,08; 1,06; 1,03; dan 1,01. Faktor koreksi apabila panjang laktasi 309-312 adalah 0,99.

\section{HASIL DAN PEMBAHASAN}

\section{Umur Beranak}

Induk sapi memiliki rataan umur beranak pertama

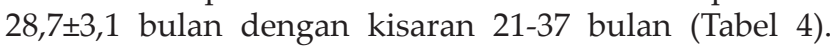
Hasil ini lebih lama daripada yang disarankan para ahli, yaitu 22-24 bulan (Pirlo et al., 2000; Etterna \& Santos, 2004) atau 21-29 bulan di Saudi Arabia (Ali et al., 2000). Hal ini berarti bahwa sapi-sapi di BBPTU mengalami penundaan kawin pertama. Kondisi tersebut diduga disebabkan oleh faktor bobot tubuh yang diinginkan belum tercapai pada saat umur kawin pertama. Selain itu suhu dan kelembaban yang tinggi juga merupakan salah satu faktor yang dapat mempengaruhi umur kawin pertama menjadi lebih tua. Faktor-faktor yang menyebabkan penundaan umur kawin pertama adalah berahi yang terlambat, kesalahan dalam deteksi berahi, kurangnya bobot badan, dan faktor lingkungan (Pirlo et al., 2000; Heinrichs et al., 2005). Menurut Nilforooshan \& Edriss (2004), terjadi efek yang positif pada pengurangan umur beranak pertama terhadap produksi susu dan umur produktif sapi.

Walaupun rataan umur beranak pertama di BPPTU lebih tua daripada di daerah beriklim sedang, tetapi masih lebih muda dibandingkan dengan beberapa daerah di pulau Jawa. Sebagai contoh, umur beranak pertama di Indonesia menurut Toharmat et al. (2007) adalah di atas 30 bulan sehingga diperlukan indikator sebagai pengembangan sistem budidaya sapi perah untuk umur beranak pertama pada tahun 2008, 2010, dan 2015, yaitu 30, 24, dan 24 bulan.

\section{Masa Kosong (Days Open)}

Rataan masa kosong (days open) sapi di BBPTU adalah 138,8 $\pm 67,9$ hari, dengan kisaran 71-207 hari (Tabel 4). Sapi di BBPTU mempunyai rataan masa kosong yang kurang baik karena mempunyai masa kosong lebih dari 
Tabel 4. Rataan produktivitas sapi perah Holstein di Balai Besar Pembibitan Ternak Unggul (BBPTU) Baturaden

\begin{tabular}{ccccccc}
\hline Laktasi ke & $\begin{array}{c}\text { Umur beranak } \\
\text { (bulan) }\end{array}$ & $\begin{array}{c}\text { Masa kosong } \\
\text { (hari) }\end{array}$ & $\begin{array}{c}\text { Selang waktu } \\
\text { beranak (hari) }\end{array}$ & $\begin{array}{c}\text { Service per } \\
\text { conception } \\
\text { (S/C) }\end{array}$ & $\begin{array}{c}\text { Jarak waktu } \\
\text { kawin pertama } \\
\text { setelah beranak } \\
\text { (hari) }\end{array}$ & $\begin{array}{c}\text { Masa laktasi } \\
\text { (hari) }\end{array}$ \\
\hline 1 & $28,70 \pm 3,05$ & $157,56 \pm 71,41$ & $435,12 \pm 71,70$ & $2,06 \pm 1,10$ & $95,00 \pm 53,37$ & $334,30 \pm 64,80$ \\
2 & $43,08 \pm 3,78$ & $128,24 \pm 57,34$ & $406,82 \pm 56,35$ & $1,86 \pm 0,90$ & $84,94 \pm 41,87$ & $303,76 \pm 48,30$ \\
3 & $56,76 \pm 4,69$ & $130,52 \pm 71,27$ & $409,5 \pm 70,85$ & $2,04 \pm 1,30$ & $81,24 \pm 40,66$ & $308,42 \pm 65,97$ \\
Rataan & $43,00 \pm 12,00$ & $138,77 \pm 67,88$ & $417,15 \pm 67,45$ & $1,99 \pm 1,10$ & $87,06 \pm 45,72$ & $315,00 \pm 61,30$ \\
\hline
\end{tabular}

120 hari. Menurut Murray (2009), masa kosong yang baik adalah 100 hari, dan dibutuhkan perbaikan apabila masa kosong lebih dari 120 hari. Namun demikian, kondisi di BBPTU ini lebih baik daripada di Rawa Seneng Jawa Tengah yang berkisar 120-196 hari, tergantung bulan beranaknya (Toharmat et al., 2007).

Masa kosong dipengaruhi oleh banyak faktor, diantaranya: patologis, hereditas, penanganan, dan jenis kelamin keturunan, dalam hal ini anak jantan mempunyai masa kosong lebih singkat (Izquierdo et al., 2008). Menurut Izquierdo et al. (2008), periode masa kosong adalah 85-115 hari setelah beranak yang merupakan masa untuk deteksi awal kelainan reproduksi dan indikator efisiensi reproduksi.

Jika diamati lebih rinci, maka rataan masa kosong sapi-sapi di BBPTU pada laktasi 1, 2, dan 3 masingmasing adalah $158 \pm 71,128 \pm 57$, dan $131 \pm 71$ hari. Rataan ini lebih lama daripada yang dilaporkan oleh Mitchell et al. (2005) dan Turkylenaz (2005). Menurut Turkylenaz (2005), masa kosong untuk laktasi 1, 2, dan 3 masingmasing adalah 115, 119, dan 112 hari.

\section{Masa Laktasi dan Produksi Susu}

Rataan masa laktasi sapi perah di BBPTU adalah $315 \pm 61$ hari dengan rataan selang beranak $417 \pm 68$ hari (Tabel 4). Rataan produksi susu SD 305 hari tertinggi terjadi pada sapi laktasi kedua, sedangkan produksi susu SD 305 hari terendah terjadi pada sapi laktasi ketiga (Tabel 5). Hal ini diduga karena pada laktasi kedua merupakan kondisi tubuh terbaik, sedangkan sapi pada laktasi ketiga kondisi tubuhnya sudah menurun, akibat pertumbuhan yang tidak baik pada masa sebelum laktasi. Hal ini terlihat dari data rataan umur beranak pertama (28,7 bulan) yang lebih dari 24 bulan, sehingga terjadi penurunan kondisi tubuh dengan meningkatnya periode laktasi. Abeni et al. (2000) dan Zanton \& Heinrichs (2005) menunjukkan bahwa sapi perah yang mengalami pertumbuhan terhambat (dengan pertambahan bobot badan kurang dari 0,6 kg/hari) pada masa sebelum dan sesudah puber sampai kawin pertama akan menghasilkan produksi susu yang lebih sedikit pada laktasi-laktasi selanjutnya.

Secara keseluruhan rataan produksi susu SD 305 hari induk sapi di BBPTU Baturraden sebesar 4.804,8 $\mathrm{kg}$ per ekor per laktasi atau 15,75 kg per ekor per hari. Tingkat produksi susu di BBPTU tersebut sangat rendah apabila dibandingkan pernyataan Vanraden et al. (2006), bahwa lama laktasi pada periode laktasi 1, laktasi 2, dan laktasi 3 adalah 336, 322 dan 306 hari, dengan tingkat produksi susu 9.364, 10.701, dan $10.876 \mathrm{~kg}$.

\section{Kawin Pertama Setelah Beranak}

Rataan jarak waktu kawin pertama setelah beranak induk sapi di BBPTU adalah 87,1 $\pm 45,7$ hari dengan kisaran 36-282 hari. Nilai rataan kawin pertama setelah beranak ini berada pada kisaran yang disarankan oleh Mitchell et al. (2005), yaitu 85,6 hari pada laktasi 1 dan 85,9 hari pada laktasi 2. Menurut Norman et al. (2009), kawin pertama setelah beranak pada sapi $\mathrm{FH}$ adalah 78-92 hari dan sapi berusia lebih tua mempunyai jarak waktu kawin pertama setelah beranak lebih panjang daripada sapi berusia lebih muda. Berdasarkan pernyataan tersebut dapat dikatakan bahwa selang waktu

Tabel 5. Rataan produksi susu SD 305 hari berdasarkan periode laktasi sapi perah di Balai Besar Pembibitan Ternak Unggul (BBPTU) Baturraden

\begin{tabular}{ccc}
\hline $\begin{array}{c}\text { Umur beranak } \\
\text { (bulan) }\end{array}$ & n (ekor) & $\begin{array}{c}\text { Rataan produksi susu } \\
\text { SD 305 hari }(\mathrm{kg})\end{array}$ \\
\hline Laktasi 1 & 1 & 4761,49 \\
$<24$ & 34 & 4798,34 \\
$24-29$ & 13 & 4845,6 \\
$30-35$ & 2 & 4468,69 \\
$36-41$ & & 4718,53 \\
Rataan & & \\
Laktasi 2 & 17 & 4739,45 \\
$36-41$ & 27 & 4969,32 \\
$42-47$ & 6 & 4966,76 \\
$48-53$ & & 4891,84 \\
Rataan & & \\
Laktasi 3 & 10 & 4688,34 \\
$48-53$ & 28 & 4706,34 \\
$54-59$ & 10 & 4590,7 \\
$60-65$ & 2 & 5888,73 \\
$66-71$ & & 4661,79 \\
Rataan & 150 & 4804,82 \\
Total & & \\
\hline & & \\
& & \\
\hline
\end{tabular}




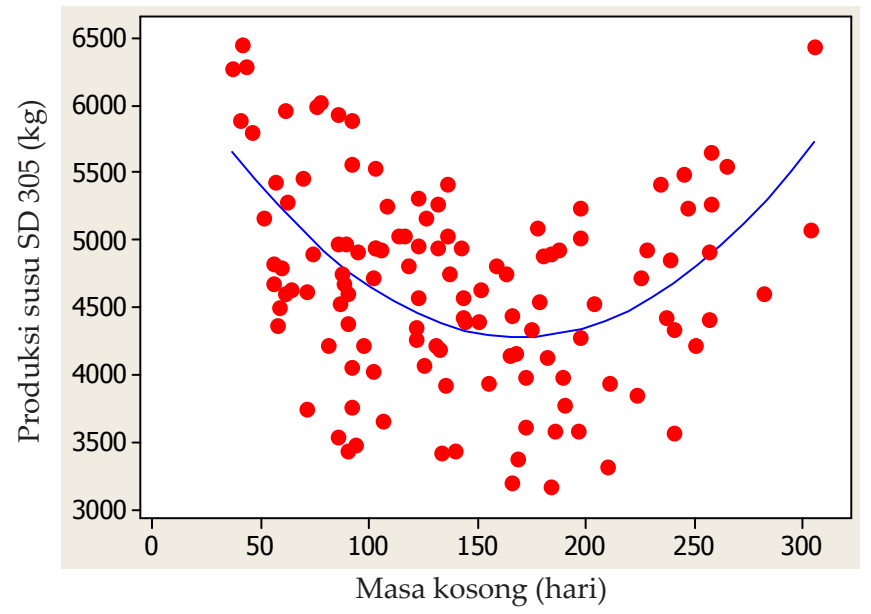

Gambar 1. Plot hubungan masa kosong dengan produksi susu SD 305 hari

kawin pertama setelah beranak pada induk sapi di BBPTU tersebut tergolong baik.

\section{Hubungan antara Masa Kosong dan Produksi Susu SD 305 Hari}

Masa kosong dan produksi susu SD 305 hari mempunyai kecenderungan mengikuti persamaan kuadratik dengan persamaan $\mathrm{Y}=6.511-26,30 \mathrm{X}+0,07763 \mathrm{X}^{2}$ dan $\mathrm{R}^{2}=25,1 \%$ (Gambar 1$)$. Nilai $\mathrm{R}^{2}=25,1 \%$ adalah sangat kecil tetapi berpengaruh sangat nyata. Hal tersebut berarti bahwa pengaruh masa kosong sangat kecil untuk keragaman yang dihasilkan pada produksi susu, dan terdapat faktor-faktor lain sebesar $74,9 \%$ diluar masa kosong yang dapat menyebabkan keragaman produksi susu.

Persamaan kuadratik tersebut memperlihatkan bahwa apabila terjadi pertambahan masa kosong akan mengakibatkan penurunan produksi susu SD 305 hari dan akan mencapai titik minimum pada hari ke-169. Hal ini sesuai dengan pendapat Atil (1999) bahwa masa kosong secara nyata berpengaruh terhadap produksi susu secara polinomial. Produksi susu SD 305 hari akan menurun sebesar $26,15 \mathrm{~kg}$ per hari untuk total produksi apabila masa kosong bertambah sehari pada selang 36-169 hari. Menurut Ali et al. (2000), masa kosong mempengaruhi produksi susu. Jika masa kosong kurang dari 60 atau lebih dari 150 hari, maka akan terjadi perbedaan produksi susu sebesar 1.021 liter. LeBlanc (2005) menyatakan bahwa masa kosong selain mempengaruhi produksi susu pada laktasi yang berjalan juga menentukan keberhasilan breeding dan selang beranak.

Penurunan produksi susu yang disebabkan pertambahan masa kosong pada selang waktu 36-169 hari setelah beranak dapat disebabkan oleh pengaruh negatif dari kebuntingan dan estrus. Semakin lama masa kosong maka akan semakin sering siklus estrus yang dialami sapi tersebut sebelum bunting. Produksi susu akan meningkat seiring dengan bertambahnya masa kosong di atas 169 hari. Hal tersebut dapat terjadi karena sapi yang memiliki masa kosong lebih lama dari
169 hari tidak mengalami dampak negatif kebuntingan hingga produksi lengkap 305 hari.

\section{KESIMPULAN}

Masa kosong berpengaruh terhadap keragaman produksi susu mengikuti pola regresi kuadratik meskipun pengaruhnya sangat kecil. Pertambahan masa kosong mengakibatkan estimasi produksi susu berkurang dan mencapai titik minimum pada masa kosong 169 hari.

\section{DAFTAR PUSTAKA}

Abeni, F., L. Calamari, L. Stefani, \& G. Pirlo. 2000. Effects of daily gain in pre- and postpubertal replacement dairy heifers on body condition score, body size, metabolic profile and future milk production. J. Dairy Sci. 83: 1468-1478.

Ali, A. K. A., A. Al-Haidary, M. A. Alshaikh, M. H. Gamil, \& E. Hayes. 2000. Effect of days open on the lactation curve of Holstein cattle in Saudi Arabia. J. Anim. Sci. 13: 277-286.

Atil, H. 1999. Genetic relationship between days open and days dry with milk yield in a herd of Holstein Friesian cattle. Pak. J. Biol. Sci. 2: 60-64.

Brotherstone, S., R. Thomson, \& I. M. S. White. 2003. Effects of pregnancy on dairy milk yield of Holstein Friesian dairy cattle. Livestock Production Science 87: 265-269.

Cole, J. B. \& D. J. Null. 2003. Genetic evalutions of lactation persistency for five breeds of dairy cattle. J. Dairy Sci. 92: 2248-2258.

Dematawewa, C. M. B., R. E. Pearson, \& P. M. VanRaden. 2007. Modeling extended lactations of Holstein. J. Dairy Sci. 90: 3924-3936.

Ettema, J. F. \& J. E. P. Santos. 2004. Impact of age at calving lactation, reproduction, health and income in first parity Holsteins on commercial farms. J. Dairy Sci. 87: 2730-2742.

Grossman, M. \& W. J. Koops. 2003. Modeling extended lactation curve of dairy cattle : A. biological basis for multiphasis approach. J. Dairy Sci. 86: 988-998.

Hafez, E. S. E. 2000. Reproduction in Farm Animal. Ed.7 $7^{\text {th }}$. Lea \& Febiger, Philadelphia.

Heinrichs, A. J., B. S. Heinrichs, O. Harel, G. W. Rogers, \& N. T. Place. 2005. A prospective study of calf factor affecting 
age, body size and body condition score at first calving of Holstein dairy heifer. J. Dairy Sci. 88: 2828-2835.

Izquierdo, C. A., V. M. X. Campos, C. G. R. Lang, J. A. S. Oaxaca, S. C. Suares, C. A. C. Jimenez, M. S. C. Jimenez, S. D. P. Betancurt, \& J. E. G. Liera. 2008. Effect of the offsprings sex on open days in dairy cattle. J. Ani. Vet. Adv. 7: 1329-1331.

LeBlanc. 2005. Overall reproductive performance of Canadian dairy cows challenge we are facing. Advance in Dairy Technology 17: 137.

Lee, J. K., P. M. VanRaden, H. D. Norman, G. R. Wiggans, \& T. R. Meinert. 1997. Relationship of yield during early lactation and days open during current lactation with 305 days yield. J. Dairy Sci. 80 : 771-776.

Mitchell, R. G., G. W. Rogers, C. D. Dechow, J. E. Vallemont, J. B. Cooper, V. S. Nielsen, \& J. S. Clay. 2005. Milk urea nitrogen concentration: heritability and genetic corelation with reproductive performance and disease. J. Dairy Sci. 88: $4434-4440$

Murray, B. B. 2009. Maximazing conception rate in dairy cows: heat detection. Queens Printer for Ontario. http://www.omafra.gov.on.ca/english/livestock/dairy/ faacts/84.048.htm.

Nilforooshan \& M. A. Edriss. 2004. Effect of age at first calving and some productive and longevity traits in Iranian Holstein of Isfahan Province. J. Dairy Sci. 87: 2130-2135.

Norman, H. D., P. M. VanRaden, J. R. Wright, \& J. S. Clay. 1999. Comparison of test interval and best prediction methods for estimation of lactation yield from monthly, a.m.-p.m., and trimonthly testing. J. Dairy Sci. 82: 2438-2444.

Norman, H. D., J. R. Wright, S. M. Hubbard, R. M. Miller, \& J. L. Hutchison. 2009. Reproductive status of Holstein and Jersey cows in the United States. J. Dairy Sci. 92: 3517-3528.

Oseni, S., I. Misztal, S. Tsuruta, \& R. Rekaya. 2003. Seasonality of days open in US Holstein. J. Dairy Sci. 86: 3718-3725.

Pirlo, G., F. Milflior, \& M. Speroni. 2000. Effect of age at first calving on production traits and difference between milk yield and returns and rearing cost in Italian Holsteins. J. Dairy Sci. 83: 603-608.

Pszczola, M., I. Aguilar, \& I. Misztal. 2009. Short communication: Trend for monthly change in days open in Holsteins. J. Dairy Sci 92: 4689-4696.

Steel, R. G. D. \& J. H. Torrie. 1997. Prinsip dan Prosedur Statistika. PT. Gramedia. Terjemahan B. Sumantri. Jakarta.

Toharmat, T., R. R. Noor, Nahrowi, R. R. A. Maheswari, L. Abdullah, D. Evvyernie, C. Sumantri, A. D. Lubis, I. G. Permana, Burhanudin, A. Setiana, A. Atabany, I. Komala, Hamzah, F. Luthan, T. Setiawati, Yulizar, D. Wahyuni, G. Santoso, N. L. Tobing, \& D. Rahayu. 2007. Review agribisnis persusuan di Indonesia. Kerjasama Tim Fakultas Peternakan IPB dan Deptan, Jakarta.

Turkylenaz, M. K. 2005. Reproductive characteristic of Holstein cattle reared in a private dairy cattle enterprase in Aydin. Turk. J. Vet. Anim. Sci. 29: 1049-1052.

VanRaden, P. M., C. M. B. Dematawewa, R. E. Pearson, \& M. E. Tooker. 2006. Productive life including all lactations and longer lactations with diminishing credits. J. Dairy Sci. 89: 3213-3220.

Webster, J. 1993. Understanding The Dairy Cow. $2^{\text {nd }}$ Ed. Blackwell Scientific Publications, Oxford.

Zanton, G. I. \& A. J. Heinrichs. 2005. Meta-analysis to assess effect of prepubertal average daily gain of Holstein heifers on first lactation production. J. Dairy Sci. 88: 3860-3867. 